\title{
Clinical Studies of Dental Erosion and Erosive Wear
}

\author{
M.C.D.N.J.M. Huysmans ${ }^{a}$ H.P. Chew ${ }^{b}$ R.P. Ellwood ${ }^{b}$ \\ ${ }^{a}$ College of Dental Science, Radboud University Nijmegen Medical Centre, Nijmegen, The Netherlands; \\ ${ }^{b}$ Dental Health Unit, University of Manchester, Manchester, UK
}

\section{Key Words}

Abrasion $\cdot$ Clinical methodology $\cdot$ Clinical trials $\cdot$ Dental erosion - Erosive wear

\begin{abstract}
We define erosion as a partial demineralisation of enamel or dentine by intrinsic or extrinsic acids and erosive tooth wear as the accelerated loss of dental hard tissue through the combined effect of erosion and mechanical wear (abrasion and attrition) on the tooth surface. Most experts believe that during the last decade there has been a significant increase in the prevalence and severity of erosive tooth wear, particularly in adolescents. Even when erosive wear occurs in its milder forms, this is a matter of concern, as it may compromise the integrity of an otherwise healthy dentition in later life. The erosive wear process is complicated and modified by many chemical, behavioural and associated processes in the mouth. If interventions are to be developed it is therefore important that in vivo methods are developed to assess the outcomes of the erosion and erosive wear processes and the effects of interventions upon them. This paper discusses potential methods of investigating erosion and erosive wear in vivo and the difficulties associated with clinical studies.
\end{abstract}

Copyright $\odot 2011$ S. Karger AG, Basel
(C) 2011 S. Karger AG, Basel

0008-6568/11/0457-0060\$38.00/0

Fax +4161306 1234

E-Mail karger@karger.ch

www.karger.com
Accessible online at: www.karger.com/cre
Tooth wear has been described as presenting itself in different types: abrasion, attrition and erosion being the most common. Dental erosion has been defined as a chemical process that involves the dissolution of enamel and dentine by acids not derived from bacteria when the surrounding aqueous phase is undersaturated with respect to tooth mineral [Larsen, 1990]. Erosion results in the softening of enamel and dentine, which, in combination with mechanical factors such as abrasion and attrition, results in accelerated, pathological wear of the teeth. Although the terms dental erosion and dental erosive wear are often considered synonymous, we will refer to this erosion-facilitated wear as 'erosive wear', reserving the term erosion only for the chemical process as defined above. The clinical condition of erosive tooth wear is recognised to have a multifactorial etiology [Young et al., 2008]. Together with the limitations in our clinical detection of signs of 'pure' erosive wear, this suggests that wear types are not mutually exclusive, but rather reflect overlapping zones in an etiological spectrum.

The histopathological aspects of both enamel and dentine erosion are described by Lussi et al. [2011]. The generalised pathological wear resulting from erosion may compromise the health of individual teeth and of the entire dentition.

The rate and severity of erosive wear result from the interplay between several chemical, biological and be- 
havioural factors. Although some of these factors may be modelled in vitro or in situ to some degree, all factors interact and contribute to the clinical manifestation of erosive wear only in vivo. Therefore, for a final validation of the results of in vitro and in situ modelling, clinical studies using the natural dentition of appropriate study populations are necessary.

\section{Epidemiology}

\section{Prevalence of Tooth Wear}

Tooth wear is a physiological process. Compensatory mechanisms (deposition of secondary dentine, alveolar growth and muscle adaptation) may ensure a continued functionality even with severe wear [Berry and Poole, 1976]. However, in a population with an increased life expectancy and with increased emphasis on the aesthetic and phonetic functions of teeth, severe wear may be considered pathological. Physiological tooth wear coupled with a cumulative damage profile will result in an agerelated prevalence of the condition, which has been confirmed for adults and deciduous teeth in children in systematic reviews [van't Spijker et al., 2009; Kreulen et al., 2010]. A prevalence of severe tooth wear (established wear into dentine) of $3 \%$ at the age of 20 years was predicted, increasing to $17 \%$ at the age of 70 years. What proportion of the prevalence should be considered pathological is not clear, nor is the proportion of erosive wear.

\section{Prevalence of Erosive Wear}

Reports of the prevalence of erosive wear vary widely, the ranges of prevalence being $6-50 \%$ in pre-school children, $11-100 \%$ in adolescents (9-17 years old) and $4-82 \%$ in adults [Jaeggi and Lussi, 2006]. The wide ranges may reflect actual population differences, but are more likely to reflect different diagnostic criteria and thresholds. Considering the high reported prevalence of erosive wear and the relatively low prevalence of severe tooth wear in general (3-17\% from 20 to 70 years), there is reason to suspect that the rate of progression of erosive wear varies greatly, from very mild to very aggressive. To date, factors that determine the severity of the condition have not been established, and it remains to be seen whether one preventive approach would be suitable for all grades.

There is consensus in the general dental and research communities that dental erosive wear has become more prevalent, but there is a lack of historical data to support this. Dutch studies, including successive cross-sectional surveys among school children in The Hague, appeared to show a dramatic increase over just 4 years (from 3 to 23\%) [van Rijkom et al., 2002; Truin et al., 2005]. However, in retrospect, this might be attributed to changes in diagnostic methods. An increased awareness of the problem, perhaps linked to lower caries prevalence, has been blamed for the increased reporting of erosive wear. The best indication that prevalence has truly increased is from a German study using orthodontic models, thus allowing the diagnostic methods of today to be used on historical records [Ganss et al., 2001]. This study showed an increase from $6.3 \%$ (cohort before 1990) to $15.1 \%$ (cohort after 1990) in 11-year-old children showing any sign of erosion.

\section{Incidence and Progression of Erosive Wear}

Only a few longitudinal studies have evaluated the incidence (new individuals diagnosed) or progression (increase in severity) of erosive wear, predominantly in children. Dugmore and Rock [2003] reported an incidence of erosive wear of $12.3 \%$ over a 2 -year period in a sample of 12 -year-old children. Ganss et al. [2001], using orthodontic models, observed an incidence of $18 \%$ between about 11 and 16 years of age. El Aidi et al. [2010] looked at both incidence and progression of erosive wear over 3 years in 622 children aged between 10 and 12 years at study entry. The incidence (new cases showing any erosive wear after 1.5 years) dropped markedly from $26.5 \%$ at 11 years to $6.4 \%$ at 14 years, indicating a degree of separation into cases (44\%) and no cases (66\%) at 15 years of age. Erosive wear progressed in about $30 \%$ of cases at every age level. Lussi and Schaffner [2000] reported that in a sample of 55 adults in two age groups (26-30 and $46-50$ years), there was progression of erosive wear on facial and occlusal surfaces and of wedge-shaped defects over 6 years. The increase in the defects was more marked in the older age group.

\section{Population Groups}

There are three broad potential population groups in which clinical studies could be conducted: healthy volunteers; those with evidence of current or past erosive wear, and those with aggressive erosive wear. The suitability of these groups for participation in clinical studies is discussed below.

\section{Healthy Volunteers}

Healthy volunteers are perhaps the easiest subjects to recruit for participating in clinical studies, but there are 
two major problems with this type of subject. Firstly, because these individuals have no evidence of disease it would be ethically unsound to induce significant levels of possibly irreversible erosive wear. Hence study designs should be limited to inducing an early level of demineralisation or softening that is clinically insignificant, and which could be reversed or remineralised either with an oral health care product or by the natural exposure to saliva. Secondly, the biological and behavioural characteristics of the individual and the properties of their enamel may indicate that such subjects do not respond in the same way as those with evidence of ongoing erosion. For example, mature natural dental enamel may be less susceptible to erosion than enamel that has been eroded because of changes in mineral content and surface characteristics. With these caveats in mind, healthy volunteers may be suitable for erosion studies that attempt to investigate changes in mineral loss or changes in surface characteristics.

\section{Populations with Evidence of Erosive Wear}

Identification of individuals with existing and ongoing erosive wear could be suitable for both qualitative and quantitative studies, particularly if the aim was to arrest or slow down the existing erosive process. Evidence of erosive wear does neither imply that it is still going on nor does it give an indication of its rate. Hence conducting studies in such groups may be somewhat unpredictable. However, this population group is the largest at which products to modulate the effects of erosion might be targeted, and they should be a key focus of clinical research.

\section{Populations with Aggressive Erosive Wear}

Patients with aggressive and rapidly progressing erosive wear, such as some with gastro-oesophageal reflux disease (GORD) or bulimia, might be suitable for the study of erosive wear and particularly quantitative surface loss. However, the standard care to treat the underlying condition usually involves multiple approaches, including behavioural modification and medical intervention with various drugs as well as with oral care products, and this complicates the assessment of added benefit from new products or approaches. Placebo control may not be ethically justified, although in a recent study on GORD patients a short placebo intervention (3 weeks) received ethical approval [Wilder-Smith et al., 2009]. Generally, these population groups have the greatest need for interventions to arrest erosive wear, but it is clear that preventive interventions for these extreme conditions may not be suitable for use in the widespread population.
Consequently, identification of suitable populations in which to conduct clinical studies is difficult and the conclusions that can be drawn from them are limited. For example, interventions that effectively decrease enamel softening under mild conditions may be completely ineffective for dentine wear, in more severe conditions or in a highly abrasive environment.

\section{Evaluation of Erosion and Erosive Wear}

Broadly, two approaches to conducting clinical studies might be taken, depending on whether the aim is to study erosion (chemical process) or erosive wear (the multifactorial clinical condition). Ideally, it would be desirable to test interventions on erosive wear, but this requires either complicated modelling that takes into account multiple factors, or actual clinical trials with associated high costs in time and money. As erosion precedes erosive wear and is assumed to be the overriding factor in erosive wear, studying erosion may be expected to contribute significantly to the knowledge and prevention of erosive wear.

\section{Methods of Assessing Erosion}

For assessing erosion in isolation from erosive wear, two approaches might be employed: measurement of the amount of calcium released by an erosive challenge, or quantification of changes in the optical characteristics, roughness or hardness of the partially demineralised surface.

\section{Dissolved or Mobilised Mineral}

Interventions that modulate the effects of acid dissolution by modifying the tooth surface, e.g. through incorporation of fluoride or other ions, buffering acid or protecting the tooth surface, might be assessed by chemical analysis of enamel dissolution.

In two clinical trials, labial surfaces of anterior teeth of healthy subjects were exposed to short, mild erosive challenges: $5 \mathrm{ml}$ of $0.01 \mathrm{~mol} / \mathrm{l}$ citric acid was dripped onto the tooth surface for about 50 s [Young et al., 2006]. Calcium analysis of the run-off solution provides a direct measure of the amount of enamel dissolution. In a first study, the short-term effect of different fluoride solutions on enamel erosion was evaluated by comparing the calcium loss due to the erosive challenge before and $5 \mathrm{~min}$ after the fluoride treatment [Hjortsjö et al., 2009a]. In a second study, the longer-term effects of two fluoride treatments $\left(\mathrm{SnF}_{2}\right.$ and $\left.\mathrm{HF}\right)$ were compared after $1,7,14$ and 28 days [Hjortsjö et al., 2009b]. 
The model showed differences between different fluoride treatments, and a protective effect of HF treatment up to 14 days. However, there may be some concerns regarding the model. In the short-term study of Hjortsjö et al. [2009a], a highly significant erosion-increasing effect of $\mathrm{NaF}$ treatment was found, and, similarly, an erosionincreasing effect of $\mathrm{SnF}_{2}$ was noted in the longer-term study [Hjotsjö et al., 2009b]. These results could not be explained, and no control data for untreated surfaces were available. The contribution of pellicle calcium to the measurement could not be determined.

Although this is a true clinical model, several key factors in clinical erosion and erosive wear are not taken into account. Most importantly, the erosive challenge is unnatural, as the natural mouth physiology of saliva and soft tissue is still excluded. The advantage over an in situ model, in which repeated erosive challenges are feasible and erosive wear can also be assessed, is not immediately clear.

Longbottom et al. [2008] assessed the susceptibility of enamel to erosion using a luminescent calcium-ionbinding agent as a marker for surface changes due to the release of calcium after erosive challenge. Unexposed enamel produced less luminescence than enamel exposed to erosion. Significant differences in luminescence were observed between different types of erosive challenges. The method may be useful for assessing potential erosion risks in the future.

\section{Surface Characteristics}

Developing instruments that can quantify subtle surface changes, such as early demineralisation and erosive softening in vivo, are extremely challenging. Such instruments need to be able to assess the natural enamel surface with its intrinsic curvature and the natural dentine surface with its persistent demineralised organic matrix. In addition, when small amounts of mineral loss are to be monitored, the tooth surface should be placed in as reproducible a position as possible for measurement, because surfaces are often inhomogeneous. Although Fosse et al. [1986] have developed an instrument for measuring microhardness in the mouth, it has not been adequately tested [Schlueter et al., 2011]. Accurate intra-oral measurements of this and other properties of tooth surfaces, such as roughness, require extensive development work.

\section{Optical Detection of Surface Demineralisation}

In general, potential methods of qualitatively assessing early erosion are based on the optical properties of enamel or dentine. The principle of these methods is that after erosion the tooth surface is roughened and porous, and thus will scatter more light and transmit less than sound tissue. Methods such as laser light backscattering, previously investigated for the detection and measurement of early caries lesions, might also be applicable to dental erosion [Angmar-Månsson and ten Bosch, 1987]. However, currently, the two most promising methods of assessing the surface characteristics of enamel in vivo are quantitative light-induced fluorescence (QLF) and optical coherence tomography (OCT).

QLF is a non-invasive optical technique initially developed for in vivo measurement of early caries [de Josselin de Jong et al., 1995] and since used extensively for investigation of caries and to a lesser extent fluorosis [Pretty et al., 2006].

In order for the method to be used to measure erosion, an area with little or no surface scattering needs to be employed as a reference area to calculate relative loss of fluorescence $(\Delta F)$ in the test area. In practice, this might be achieved by either protecting part of the surface prior to erosion or alternatively it might be possible to use a fluid, e.g. water, which will reduce scattering in the reference area.

In vitro studies attempting to validate the use of QLF for quantifying acid erosion of enamel have used $\Delta \mathrm{Q}$ (the product of $\Delta \mathrm{F}$ and lesion area) as the outcome variable. Pretty et al. [2004] demonstrated the ability of QLF to detect and longitudinally monitor erosion on unpolished enamel surfaces subjected to 30-min intervals of erosion for up to $15 \mathrm{~h}$. Elton et al. [2009] found a weak correlation of 0.22 between $\Delta \mathrm{Q}$ and integrated mineral loss by transverse microradiography, and they concluded that QLF is reliable for shallow erosive lesions but becomes less consistent as erosion advances. QLF may have the potential to measure early erosion in vivo, particularly in its earlier stages prior to surface loss, but a significant amount of work is required to validate it clinically.

OCT has developed rapidly in recent years in terms of resolution, data acquisition speed, tissue penetration, contrast enhancement and delivery systems for clinical application. The method provides cross-sectional imaging by measuring the magnitude and echo time delay of backscattered light. The increased porosity of demineralised enamel, compared to sound enamel, results in a change in optical property, and hence a difference in intensity of the reflected light can also be quantified and analysed [Amaechi et al., 2003; Popescu et al., 2008].

For dental erosion, the method is based upon quantitative measurements of the backscattered light intensity at the surface, which indicates surface porosity and also 
depth of penetration of the region of interest, which is reduced when surface scattering occurs. Using this approach, the increased porosity of demineralised enamel compared to sound enamel can be estimated (fig. 1). Recently, OCT was used to quantify demineralisation in an in vivo study of the effectiveness of a treatment for GORD [Wilder-Smith et al., 2009]. A significantly reduced intensity of backscattered light was observed in the treatment group compared to the placebo group.

OCT provides real-time imaging and does not require specimen processing. It is non-invasive and can potentially measure both surface characteristics and quantitative loss of tooth structure (fig. 2). Ideally, as with other techniques of this type, accurate repositioning of the probe is required, so that the same area is measured at different time points. An area of no change may also be required for reference.

\section{Methods of Assessing Erosive Wear}

Objective in vivo assessment of erosive wear is difficult because surface loss generally progresses slowly and current methods have generally low resolution and require extended observation periods to detect changes reproducibly. Not least of the challenges is the identification of a stable reference from which loss of tooth substance can be gauged. In many populations, erosive wear is often seen as cuspal cupping on first molars, and ideally any instrumental technique that is developed should allow monitoring of these teeth.

\section{Clinical Scoring Methods}

An ideal scoring method for measurement of erosive wear over time should be simple to understand and use, clear in its criteria and reproducible. Many different erosion and tooth surface loss indices have been developed and used for epidemiological and clinical purposes. Most combine quantitative and qualitative criteria and rely in part on assessing the presence or absence of dentine exposure. Quantitative criteria used are objective physical measurements, such as the area of worn surfaces and depth of cuspal cupping.

Eccles [1978] originally classified lesions broadly as early, small and advanced, with no strict criterion definitions, thus allowing wide interpretation. Later, the scoring method was refined and expanded, with greater emphasis on the descriptive criteria [Eccles, 1979]. It not only graded severity of erosion but also site of erosive wear and is considered one of the cardinal indices from which others have evolved. Smith and Knight [1984] took Eccles' idea a stage further and produced the tooth wear index,
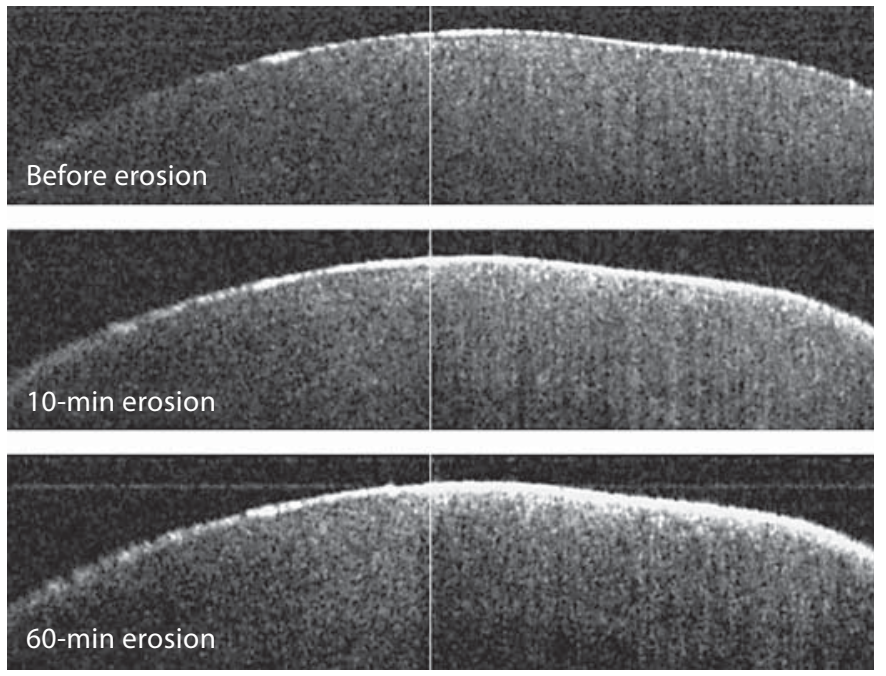

Control

Eroded

Fig. 1. Surface change (increased surface light backscattering) visualised with OCT at baseline and after 10 and 60 min of erosion in orange juice.

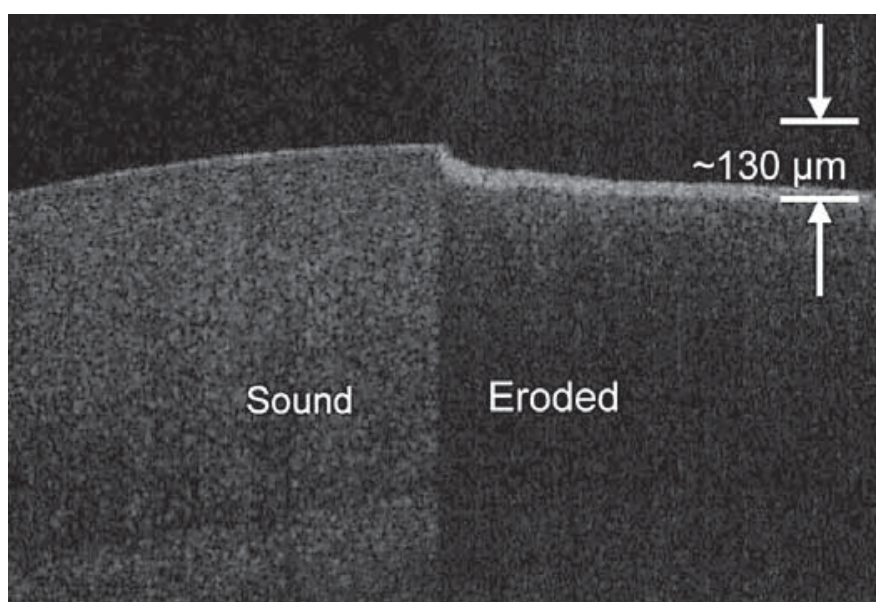

Fig. 2. Surface loss visualised as a step change with OCT after erosion in orange juice for $24 \mathrm{~h}$.

in which all four visible surfaces of every tooth are scored for wear, irrespective of its aetiology. Millward et al. [1994] made adjustments to the tooth wear index to study erosive wear in the primary and young secondary dentitions, excluding cervical surfaces. Linkosalo and Markkanen [1985] utilised a qualitative score with listed diagnostic criteria and a four-point scale to grade severity of erosion. Their scoring system was then modified by Lus- 
Table 1. Erosion index according to Lussi [1996]

\begin{tabular}{ll}
\hline Score & Criteria \\
\hline Facial & surface \\
0 & $\begin{array}{l}\text { No erosion; surface with a smooth, silky-glazed } \\
\text { appearance, possible absence of developmental ridges }\end{array}$ \\
1 & $\begin{array}{l}\text { Loss of surface enamel; intact enamel cervical to the } \\
\text { erosive lesion; concavity on enamel where breadth clearly } \\
\text { exceeds depth, thus distinguishing it from tooth brush } \\
\text { abrasion; undulating borders of the lesion are possible } \\
\text { and dentine is not involved }\end{array}$ \\
& $\begin{array}{l}\text { Involvement of dentine for less than half of the tooth } \\
\text { surface }\end{array}$ \\
& $\begin{array}{l}\text { Involvement of dentine for more than half of the tooth } \\
\text { surface }\end{array}$ \\
\hline $\begin{array}{l}\text { Occlusal and lingual surfaces } \\
\text { No erosion; surface with a smooth, silky-glazed } \\
\text { appearance, possible absence of developmental ridges }\end{array}$ \\
$\begin{array}{l}\text { Slight erosion, rounded cusps, edges of } \\
\text { restorations rising above the level of the adjacent tooth } \\
\text { surface, grooves on occlusal aspects; loss of surface } \\
\text { enamel; dentine is not involved }\end{array}$ \\
$\begin{array}{l}\text { Severe erosions, more pronounced signs than in grade 1; } \\
\text { dentine is involved }\end{array}$ \\
2
\end{tabular}

si [1996] to create an erosive wear score that has been extensively used by European researchers to score labial, lingual and occlusal surfaces of all teeth except the third molars (table 1).

The methods described above have been used mainly in epidemiological settings. For clinical use, Oilo et al. [1987] pioneered a different type of scoring system, with its criteria based upon treatment need, but this approach requires experience for reliable use because individuals with differing clinical backgrounds could produce differing results. Also, treatment need is not only determined by the degree of wear, but also by the patient's subjective problem. There have also been attempts to visualise, measure and monitor the amount of worn enamel or exposed dentine indirectly on serial study casts [Fareed et al., 1990; Schlueter et al., 2005].

The most recent scoring system, the basic erosive wear examination, was developed for use in general practice and to allow comparison with other indices [Bartlett et al., 2008]. Each sextant is scored independently, and a score is applied, which is linked to the clinical management of the condition. It is hoped that this approach will be adopted internationally to allow comparison of studies.

Clinical Studies
It is doubtful whether any of the approaches described are sensitive enough to permit wear to be monitored within a reasonable time, and they cannot be used readily to measure the rate of erosive wear. To date, there is not one method that meets all the requirements of clinical staging and longitudinal monitoring of erosive tooth wear.

\section{Indirect Profilometry}

To date, few studies monitoring erosive wear using indirect profilometry have been described. Two studies involved cementing a metal marker onto the palatal surfaces of upper incisors as a reference point. Erosion or tooth wear was then estimated by scanning either impressions or study casts with surface profilometry at regular intervals [Bartlett et al., 1996; Schlueter et al., 2005]. The principle of this method is to measure step height between the unchangeable reference area and an experimental area that is exposed to erosive challenges: an increasing step height in sequential measurements indicates a progression of tissue loss [Ganss et al., 2005]. One disadvantage of this approach is that it is a relatively invasive procedure.

The method has been used in a clinical trial of the effect of a bonding agent application on the wear of exposed dentine on anterior palatal surfaces [Sundaram et al., 2007b]. The majority of the subjects had suspected erosive wear. The study had a split-mouth design and lasted 20 months. Apart from attrition, the main problem was loss of the metal reference discs: $25 \%$ by 3 months, $50 \%$ by 9 months and virtually all by 20 months. The study was further complicated by the preventive measure changing the baseline surface height, thus making true dentine wear more difficult to determine. However, the difference in 'wear' between resin-covered and control teeth at 3 months was statistically significant.

The method seems appropriate for longer-term evaluation of erosive wear. It could also be applied to enamel wear measurements. Obviously, enough inter-occlusal space is required for the metal references not to interfere with occlusion and articulation, and this application of profilometry to assessing occlusal wear may be difficult for that reason. Better retention of the references is necessary, but other materials, such as composite resins, may be considered where mechanical wear is expected to be negligible.

Other systems generate superimposed three-dimensional (3D) digital images by profiling consecutive dental casts with a null-contact profiler [Pintado et al., 1997; Pesun et al., 2000] or with an optical 3D sensor [Mehl et 
al., 1997]. Direct 3D scanning of a tooth or surface using the systems developed for CAD CAM preparation of restorative materials or modifications thereof also represent a potential solution to measuring tooth wear in vivo. Again, a significant amount of work may be required before these systems can be adapted for this task.

\section{Measurements of Enamel Thickness}

Currently, two clinically applicable methods for directly measuring enamel layer thickness are available: OCT (fig. 2) and ultrasound [Huysmans and Thijssen, 2000]. For methods measuring the thickness of the enamel layer, the problem of finding a stable reference is solved, as the amelodentinal junction is stable. However, enamel thickness is very location dependent and, in particular, it becomes thinner towards the cervical region, so the main problem is that of ensuring that the same measurement site is used at each time point. Using an elaborate method of holes drilled into an impression of the subject's jaw, to ensure good OCT probe positioning, thickness changes within the micrometre range could be measured [WilderSmith et al., 2009]. Without such repositioning, ultrasound was estimated to have a measurement resolution of more than $300 \mu \mathrm{m}$ in a simulated clinical set-up [Louwerse et al., 2004].

Enamel layer thickness reduction was the main outcome parameter in the study by Wilder-Smith et al. [2009] on 30 GORD patients, which lasted only 3 weeks. The measurement error was reported to be well below $10 \%$, and the threshold for wear detection was in the range of 5-10 $\mu \mathrm{m}$. After 3 weeks, a significant wear reduction of about $50 \%$ (7.2 vs. $15.3 \mu \mathrm{m})$ was seen.

A few questions remain regarding this measurement technique. For instance, the average enamel layer thickness reported by Wilder-Smith et al. [2009] was more than $2 \mathrm{~mm}$ : this seems extremely high for severe wear patients. Also, although the authors reported that measurement was 'relatively unproblematic', it appears to be time consuming and complex, and this might limit its use in larger groups. Because the method relies on the amelodentinal junction as a reference, it cannot be used to measure tissue loss once the dentine has been reached.

The combination of aggressive erosive wear with a very precise measurement allowed for a very short trial duration in this last study. As this example involved a pharmaceutical treatment for a medical condition, it is likely that patients would continue the therapy and a longer evaluation may not be needed. In preventive treatments of erosive wear alone, where patients may have no symptoms, compliance may be more of an issue, and lon- ger-term studies would probably be needed to assess their realistic therapeutic effectiveness. However, the measurement method used is suitable also for these studies.

\section{Feasibility Aspects of Clinical Trials}

In clinical trials evaluating (prevention of) natural erosive wear, two variables are extremely important in determining the size, duration and therefore the feasibility of the study: the rate of progression and the variation in this rate. For 'mild' erosive wear, which is usually reported in surveys in children and adolescent, the rate in micrometre enamel per year is never reported, and there are only visual scoring systems to go by. El Aidi et al. [2010] found that about 30\% of erosive-wear cases showed progression over 1.5 years, suggesting that variation in rate is probably high. We recently performed a sample size calculation for an erosion prevention study in such a population of 12-year-olds with early erosion, based on the clinical scoring method only. For a treatment with an expected effect of $25 \%$ in wear reduction, the estimated group size was about 800 for an 18 -month study. To arrive at a sample of this size, 6,000 12-year-olds would need to be screened.

There are a few reports on rates of progression in aggressive erosive-wear cases. Bartlett et al. [1997] reported a palatal enamel wear rate of about $75 \mu \mathrm{m}$ per year, with a range of 35-215 $\mu \mathrm{m}$, while healthy control subjects lost about $7 \mu \mathrm{m}$ per year. The dentine wear rate of control teeth in the dentine bonding study was about $100 \mu \mathrm{m}$ per year [Sundaram et al., 2007a]. The enamel wear rate in control subjects in the GORD clinical trial was about 250 $\mu \mathrm{m}$ per year [Wilder-Smith et al., 2009]. Here, the reported variation was much lower: we estimated that the 95\% confidence interval for the rate was 175-350 $\mu \mathrm{m}$.

In caries research, it has taken a long time to move away from the cavitated lesion as the only relevant outcome of caries studies, and to include earlier stages of the disease: non-cavitated lesions. However, in caries progression, single episodes of demineralisation are not considered relevant outcomes, as caries lesions only develop when the balance between episodes of demineralisation and episodes of remineralisation is shifted towards demineralisation for a significant period of time. In research into erosion or erosive wear, the matter tends to be approached from the other side: we have studied mainly dental erosion (short episodes of acid attack) but less often the clinical outcome of erosive wear. Although there is evidence that remineralisation after an erosive attack is 
minimal, it is unclear to what level such surfaces will remineralise, if at all, and how mechanical wear modulates this process. It is not proven that preventive measures that reduce dental erosion will equally reduce erosive wear. Ideally, the validity of an isolated and early measurement of susceptibility needs to be shown in a longitudinal study evaluating the clinically relevant outcome of tissue loss.

\section{Conclusion}

Clinical trials involving patients with mild erosive wear may already be feasible using existing clinical scoring systems, but they would require large groups and several years of follow-up. An alternative would be to assess dental erosion (surface changes) in such a study, but va- lidity would then be an issue. Clinical trials involving patients with aggressive erosion have been performed, but the results may not be suitable for extrapolation to other populations.

It is clearly important that appropriate clinical methods are developed and validated to assess erosion and erosive tooth wear in vivo. New diagnostic technologies may provide solutions to this challenging task, but a significant amount of development is still required.

\section{Disclosure Statement}

Dr. Ellwood declares that he is an employee of the Colgate Palmolive Company but has no financial interest in this publication. Prof. Huysmans and Dr. Chew have no conflicts of interest.

\section{References}

Amaechi BT, Podoleanu A, Higham SM, Jackson DA: Correlation of quantitative light-induced fluorescence and optical coherence tomography applied for detection and quantification of early dental caries. J Biomed Opt 2003;8:642-647.

-Angmar-Månsson B, ten Bosch JJ: Optical methods for the detection and quantification of caries. Adv Dent Res 1987;1:14-20.

Bartlett D, Ganss C, Lussi A: Basic erosive wear examination (BEWE): a new scoring system for scientific and clinical needs. Clin Oral Investig 2008;12(suppl 1):S65-S68.

Bartlett DW, Blunt L, Smith BG: Measurement of tooth wear in patients with palatal erosion. Br Dent J 1997;182:179-184.

- Bartlett DW, Evans DF, Anggiansah A, Smith BG: A study of the association between gastro-oesophageal reflux and palatal dental erosion. Br Dent J 1996;181:125-131.

-Berry DC, Poole DFG: Attrition: possible mechanisms of compensation. J Oral Rehabil 1976;3:201-206.

-de Josselin de Jong E, Sundstrom F, Westerling $\mathrm{H}$, Tranaeus S, ten Bosch JJ, Angmar-Månsson B: A new method for in vivo quantification of changes in initial enamel caries with laser fluorescence. Caries Res 1995;29:2-7.

- Dugmore CR, Rock WP: The progression of tooth erosion in a cohort of adolescents of mixed ethnicity. Int J Paediatr Dent 2003;13: 295-303.

Eccles JD: The treatment of dental erosion. J Dent 1978;6:217-221.

Eccles JD: Dental erosion of nonindustrial origin. A clinical survey and classification. J Prosthet Dent 1979;42:649-653.
El Aidi H, Bronkhorst EM, Huysmans MC, Truin GJ: Dynamics of tooth erosion in adolescents: a 3-year longitudinal study. J Dent 2010;38:131-137.

Elton V, Cooper L, Higham SM, Pender N: Validation of enamel erosion in vitro. J Dent 2009;37:336-341.

Fareed K, Johansson A, Omar R: Prevalence and severity of occlusal tooth wear in a young Saudi population. Acta Odontol Scand 1990; 48:279-285.

- Fosse G, Rosengren B, Skaale S, Leknes K, Wulff L: An in vivo method for microhardness measurements on human teeth. Scand J Dent Res 1986;94:27-37.

Ganss C, Klimek J, Giese K: Dental erosion in children and adolescents - a cross-sectional and longitudinal investigation using study models. Community Dent Oral Epidemiol 2001;29:264-271.

Ganss C, Lussi A, Klimek J: Comparison of calcium/phosphorus analysis, longitudinal microradiography and profilometry for the quantitative assessment of erosive demineralisation. Caries Res 2005;39:178-184.

Hjortsjö C, Jonski G, Thrane PS, Saxegaard E, Young A: The effects of acidic fluoride solutions on early enamel erosion in vivo. Caries Res 2009a;43:126-131.

Hjortsjö C, Jonski G, Thrane PS, Saxegaard E, Young A: Effect of stannous fluoride and dilute hydrofluoric acid on early enamel erosion over time in vivo. Caries Res 2009b;43: 449-454.

Huysmans MC, Thijssen JM: Ultrasonic measurement of enamel thickness: a tool for monitoring dental erosion? J Dent 2000;28: 187-191.
Jaeggi T, Lussi A: Prevalence, incidence and distribution of erosion; in Lussi A (ed): Dental Erosion: From Diagnosis to Therapy. Monogr Oral Sci. Basel, Karger, 2006, vol 20, pp 44-65.

Kreulen CM, van't Spijker A, Rodriguez JM, Bronkhorst EM, Creugers NHJ, Bartlett DW: Systematic review of the prevalence of tooth wear in children and adolescents. Caries Res 2010;44:151-159.

Larsen MJ: Chemical events during tooth dissolution. J Dent Res 1990;69:575-580, discussion 634-576.

Linkosalo E, Markkanen H: Dental erosions in relation to lactovegetarian diet. Scand J Dent Res 1985;93:436-441.

Longbottom C, Perfect E, Rowley-Williams C, Pitts NB: A luminescent calcium-ion binder in the assessment of dental erosion risk/ susceptibility - an in vitro feasibility study (abstract). Caries Res 2008;42:229.

Louwerse C, Kjaeldgaard M, Huysmans MC: The reproducibility of ultrasonic enamel thickness measurements: an in vitro study. J Dent 2004;32:83-89.

Lussi A: Dental erosion clinical diagnosis and case history taking. Eur J Oral Sci 1996;104: 191-198.

-Lussi A, Schaffner M: Progression of and risk factors for dental erosion and wedge-shaped defects over a 6-year period. Caries Res 2000; 34:182-187.

Lussi A, Schlueter N, Rakhmatullina E, Ganss C: Dental erosion - an overview with emphasis on chemical and pathohistological aspects. Caries Res 2011;45(suppl 1):2-12. 
-Mehl A, Gloger W, Kunzelmann KH, Hickel R: A new optical 3-D device for the detection of wear. J Dent Res 1997;76:1799-1807.

-Millward A, Shaw L, Smith AJ, Rippin JW, Harrington E: The distribution and severity of tooth wear and the relationship between erosion and dietary constituents in a group of children. Int J Paediatr Dent 1994;4:151-157.

-Oilo G, Dahl BL, Hatle G, Gad AL: An index for evaluating wear of teeth. Acta Odontol Scand 1987;45:361-365.

- Pesun IJ, Olson AK, Hodges JS, Anderson GC: In vivo evaluation of the surface of posterior resin composite restorations: a pilot study. J Prosthet Dent 2000;84:353-359.

- Pintado MR, Anderson GC, DeLong R, Douglas $\mathrm{WH}$ : Variation in tooth wear in young adults over a two-year period. J Prosthet Dent 1997; 77:313-320.

- Popescu DP, Sowa MG, Hewko MD, Choo-Smith LP: Assessment of early demineralization in teeth using the signal attenuation in optical coherence tomography images. J Biomed Opt 2008;13:054053.

Pretty IA, Edgar WM, Higham SM: The validation of quantitative light-induced fluorescence to quantify acid erosion of human enamel. Arch Oral Biol 2004;49:285-294.
Pretty IA, Tavener JA, Browne D, Brettle DS, Whelton H, Ellwood RP: Quantification of dental fluorosis using fluorescence imaging. Caries Res 2006;40:426-434.

Schlueter N, Ganss C, De Sanctis S, Klimek J: Evaluation of a profilometrical method for monitoring erosive tooth wear. Eur J Oral Sci 2005;113:505-511.

Schlueter N, Hara A, Shellis RP, Ganss C: Methods for measurement and characterization of erosion in enamel and dentine. Caries Res 2011;45(suppl 1):13-23.

Smith BG, Knight JK: An index for measuring the wear of teeth. Br Dent J 1984;156:435438.

-Sundaram G, Wilson R, Watson TF, Bartlett D: Clinical measurement of palatal tooth wear following coating by a resin sealing system. Oper Dent 2007a;32:539-543.

Sundaram G, Wilson R, Watson TF, Bartlett DW: Effect of resin coating on dentine compared to repeated topical applications of fluoride mouthwash after an abrasion and erosion wear regime. J Dent 2007b;35:814818.

Truin GJ, van Rijkom HM, Mulder J, van't Hof MA: Caries trends 1996-2002 among 6- and 12-year-old children and erosive wear prevalence among 12-year-old children in The Hague. Caries Res 2005;39:2-8. van't Spijker A, Rodriguez JM, Kreulen CM, Bronkhorst EM, Bartlett DW, Creugers $\mathrm{NH}$ : Prevalence of tooth wear in adults. Int J Prosthodont 2009;22:35-42.

van Rijkom HM, Truin GJ, Frencken JE, Konig KG, van't Hof MA, Bronkhorst EM, Roeters FJ: Prevalence, distribution and background variables of smooth-bordered tooth wear in teenagers in The Hague, The Netherlands. Caries Res 2002;36:147-154.

Wilder-Smith CH, Wilder-Smith P, KawakamiWong $\mathrm{H}$, Voronets J, Osann $\mathrm{K}$, Lussi A: Quantification of dental erosions in patients with GERD using optical coherence tomography before and after double-blind, randomised treatment with esomeprazole or placebo. Am J Gastroenterol 2009;104:27882795.

Young A, Amaechi B, Dugmore C, Holbrook P, Nunn J, Schiffner U, Lussi A, Ganss C: Current erosion indices - flawed or valid? Summary. Clin Oral Investig 2008;12:S59-S63.

Young A, Thrane PS, Saxegaard E, Jonski G, Rolla G: Effect of stannous fluoride toothpaste on erosion-like lesions: an in vivo study. Eur J Oral Sci 2006;114:180-183. 